\title{
ESTUDO COMPARATIVO DE HEMOCULTURAS E CATETERES POSITIVOS PARA LEVEDURAS DO GÊNERO CANDIDA DE ORIGEM HOSPITALAR
}

\author{
COMPARATIVE STUDY OF BLOOD CULTURES AND CATHETERS WHICH WERE \\ POSITIVE FOR YEAST OF THE GENUS CANDIDA FROM HOSPITAL ORIGIN
}

\author{
Anelise Cristina Osorio Cesar Doria ${ }^{1}$ \\ Thaisa Baesso Santos ${ }^{1}$ \\ Fernanda Ramos Figueira ${ }^{2}$ \\ Camila Di Paula Costa Sorge ${ }^{2}$ \\ Renata Cássia Bernardes ${ }^{3}$ \\ Auricélia de Cássia Silva Batista ${ }^{4}$ \\ Sônia Khouri ${ }^{5}$
}

Resumo: Cerca de $80 \%$ das infecções fúngicas hospitalares são causadas por espécies do gênero Candida, Aproximadamente, 65\% das infecções resultam da migração de micro-organismos da microbiota da pele, a partir do sítio de inserção do cateter e ocorrem devido à formação de biofilme. O objetivo do estudo foi realizar a caracterização de leveduras do gênero Candida isoladas de cateter venoso central (CVC) e de hemoculturas de pacientes hospitalizados. A metodologia empregada foi a de identificação de amostras de CVC e hemocultura, utilizando CHROMagar®, CANDIFAST® e o método automatizado VITEK® 2 Compact. Para avaliação da formação de biofilme, utilizou-se a Microscopia Eletrônica de Varredura (MEV). Foram investigadas 18 amostras de pacientes hospitalizados, sendo encontradas 11 cepas de Candida albicans (50\%), 02 cepas de $C$. parapsilosis (9\%), 02 cepas de C. tropicalis (9\%), 01 cepa de C. glabrata (4,5\%), 01 cepa de C. pelliculosa 4,5\%), 01 cepa de $C$. guilliermondii (4,5\%) e 04 cepas de leveduras não identificadas (18\%). Na técnica de MEV, todas as amostras de cateter foram positivas para a formação de biofilme, concluindo-se que sua presença pode influenciar na candidemia hospitalar relacionada ao cateter.

Palavras-chave: gênero Candida, cateter, hemocultura, biofilme.

Abstract: About $80 \%$ of hospital fungal infections are caused by Candida species. Approximately $65 \%$ of the infections result from the migration of microorganisms of the microflora from the skin at the insertion site of the catheter and are due to biofilm formation. The aim of the study was to characterize Candida yeasts isolated from central venous catheter (CVC) and blood cultures of hospitalized patients. The methodology employed was to identify CVC and blood culture samples using CHROMagar $\AA$, CANDIFAST®, and the automated VITEK® 2 Compact. A Scanning Electron Microscopy (SEM) was used to assess biofilm formation. We investigated 18 samples from hospitalized patients, and found 11 strains of Candida albicans (50\%), 02 strains of C. parapsilosis (9\%), 02 strains of C. tropicalis (9\%), 01 strain of C. glabrata (4.5\%), 01 strain of C. pelliculosa (4.5\%), 01 strain of C. guilliermondii (4.5\%), and 04 unidentified yeast strains (18\%). SEM technique in all samples were positive for

\footnotetext{
1 Doutoranda e Mestra em Engenharia Biomédica - Universidade do Vale do Paraíba - Univap, Brasil. E-mails: ane.doria@gmail.com; thabaesso@hotmail.com.

${ }_{2}$ Graduanda em Biomedicina e Mestranda em Bioengenharia - Univap, Brasil. E-mail: ferfig510@gmail.com; cah.sorge@gmail.com.

${ }^{3}$ Especialista em Análises Clínicas de Doenças Infecciosas - Universidade de Taubaté - Unitau, Brasil e Graduada em Biologia geral - Universidade de Mogi das Cruzes - UMC, Brasil. Bióloga na Valeclin Laboratório de Análises Clínicas S/S LTDA. E-mail: renatacbernardes@ig.com.br.

${ }^{4}$ Graduada em Biomedicina - UMC, Brasil. Biomédica no Departamento de Bacteriologia - Laboratório Central da Prefeitura de São José dos Campos - PMSJC, Brasil. E-mail: auricassia@hotmail.com.

${ }^{5}$ Doutora em Microbiologia - Universidade de São Paulo - USP, Brasil e Docente da Univap, Brasil. E-mail: soniak@univap.br.
} 
catheter biofilm formation, which indicates that their presence may influence the hospital catheter-related candidemia.

Keywords: Candida; catheter; blood culture; biofilm.

\section{INTRODUÇÃO}

Em muitos hospitais utilizam-se avanços científicos, a fim de fornecer aos pacientes, diagnósticos e terapias atualizadas, ainda assim, há muitos problemas que os acompanham, dos quais, os mais antigos e temidos são as infecções hospitalares (COIMBRA, COIMBRA FILHO; LIMA, 2012). Conforme o Ministério da Saúde (MS), portaria o 2.616, de 12.05.1998, as infecções hospitalares são aquelas adquiridas após a admissão do paciente na unidade hospitalar e que se manifestam durante a internação ou após a alta (ABEGG; SILVA, 2011).

A incidência de infecções hospitalares (IHs) por fungos tem aumentado, substancialmente, nas últimas décadas, acarretando altos índices de mortalidade, atingindo até $60 \%$. Espécies do gênero Candida têm sido os agentes mais frequentemente isolados, correspondendo, aproximadamente, a $80 \%$ das infecções fúngicas de origem hospitalar, além de ser a quarta maior causa de infecção da corrente sanguínea, conduzindo ao óbito em torno de 25 a 38\% dos pacientes (TAMURA et al., 2007). Em casos de candidemia, a identificação da espécie torna-se indispensável, pois a patogenicidade e o perfil de sensibilidade a determinado antifúngico são variáveis, além de ser necessário localizar a fonte da infecção e monitorar o tratamento, reduzindo, assim, o tempo de internação e os custos hospitalares (MIMICA et al., 2009). O termo candidemia, apesar de controverso, pode ser definido como, pelo menos, uma hemocultura positiva com sinais clínicos temporalmente relacionados. Pesquisadores afirmam que ela está relacionada com os avanços técnicocientíficos da medicina e das ciências farmacêuticas, por esse motivo, existe o crescimento significativo de ensaios clínicos, estudos multicêntricos de avaliação da terapêutica antifúngica, estudos genéticos e desenvolvimento de testes laboratoriais (PÁROLA, 2011).

No início de 1940, foram introduzidos, na prática clínica, dispositivos intravasculares para auxiliar na assistência à saúde de inúmeros pacientes, especialmente, os que estavam internados em unidades de terapias intensivas (UTI) ou sob quimioterapia. Atualmente, eles se tornaram indispensáveis e amplamente aceitos, sendo utilizados, apenas nos Estados Unidos, cerca de 15 milhões de cateteres venosos centrais por ano (CORRÊA et al., 2012). Cateteres venosos centrais (CVC) são utilizados, por exemplo, para administração de medicamentos, soluções de nutrição parenteral e para facilitar o acesso vascular para hemodiálise (ROSS et al., 2006). Estima-se que, pelo menos, metade dos pacientes, admitidos em hospitais, receba terapias intravenosas (STORTI et al., 2007).

Aproximadamente, $65 \%$ das infecções resultam da migração de micro-organismos que compõem a microbiota da pele, a partir do sítio de inserção do cateter. Os fatores de risco relacionados à infecção por cateteres estão associados à duração do cateterismo, ao local de inserção, ao material do qual é constituído, à repetição do cateterismo, à manipulação 
frequente, à doença de base, à gravidade do estado clínico do paciente, e à condição imunológica do mesmo (ROSS et al., 2006).

A patogenicidade ou potencial de virulência define-se como a capacidade da levedura em aderir, infectar e causar doença, sendo determinados geneticamente e expressos quando os micro-organismos são submetidos a determinadas condições (TAMURA et al., 2007). A maioria dos micro-organismos envolvidos na colonização do cateter não são virulentos na forma planctônica, mas podem causar infecção persistente, quando estão agrupados, formando o biofilme (conjunto de micro-organismos que convivem em associação) que é preocupante, pois favorece proteção contra neutrófilos, dificultando a atividade dos antimicrobianos e o tratamento com drogas (CORRÊA et al., 2012; STORTI et al., 2007).

De uma forma geral, o processo de formação do biofilme sobre a superfície de um material ocorre em três etapas: (i) Transporte de células livres do meio líquido para uma superfície sólida e sua subsequente adsorção/adesão; (ii) Crescimento e divisão de células fixas à custa de nutrientes provenientes do líquido circundante (colonização), conjuntamente com a produção e excreção de Substâncias Poliméricas Extracelulares (EPS); e (iii) Fixação de células fúngicas flutuantes e outras partículas, contribuindo para o acúmulo do biofilme (crescimento) (SREY; JAHID; HA, 2013; TAN et al., 2014; XAVIER et al., 2003).

O presente trabalho teve como principal objetivo realizar a caracterização de leveduras do gênero Candida isoladas de cateter venoso central (CVC) e de hemoculturas de pacientes internados de um hospital público de São José dos Campos - São Paulo.

\section{METODOLOGIA}

No período de Março a Novembro de 2012, foram solicitadas 243 pesquisas de microorganismos em ponta de cateter, das quais 40 foram objeto também de pedido de hemocultura. Desse universo, o presente estudo analisou somente as amostras positivas para leveduras, que totalizaram 16 amostras de cateter venoso central (sendo que destas, 3 possuíam também amostra de hemocultura), de pacientes internados em um hospital público de São José dos Campos - SP. As amostras foram cedidas pelo Laboratório ValeClin, de São José dos Campos - SP, mantidas e processadas no Núcleo de Estudos Farmacêuticos e Biomédicos (NUFABI) da Faculdade de Ciências da Saúde e no Laboratório Central da Prefeitura de São José dos Campos - SP. O estudo obteve aprovação do Comitê de Ética em Pesquisa da Universidade de Taubaté em 23 de Fevereiro de 2012, sob protocolo CEP/UNITAU n. ${ }^{\circ}$ 542/1.

A metodologia empregada foi realizada em três etapas: 1- os segmentos de cateteres recebidos foram lavados com solução fisiológica a $0,9 \%$, transferidos para um recipiente estéril e colocados em estufa por, aproximadamente, 24 horas para a secagem. Após a secagem, os cateteres foram transferidos para um porta amostra ("stub") com um pedaço de fita de carbono coloidal para auxiliar a condutividade dos elétrons; posteriormente, foi 
realizada a metalização da superfície com banho de ouro, seguida pela análise em Microscópio Eletrônico de Varredura (MEV) - EVO MA 10, para observação da formação de biofilme; 2- a solução fisiológica utilizada na lavagem dos cateteres foi utilizada na semeadura da amostra em CHROMagar ${ }^{\circledR}$ (DIFCO) e ágar Sabouraud (DIFCO) e incubadas a $37^{\circ} \mathrm{C}$ por 48 horas. Após o período de incubação, as cepas semeadas em ágar Sabouraud (DIFCO) foram utilizadas na realização da identificação e prova de resistência a antifúngicos por meio do CANDIFAST (ELITech®) e de identificação por intermédio do método automatizado VITEK® 2 Compact (Biomérieux); 3- realizou-se a semeadura das cepas obtidas de hemocultura coletada, no momento da remoção do cateter,em CHROMagaß ${ }^{\circledR}$ (DIFCO), para a identificação presuntiva e ágar Sabouraud (DIFCO), que foi utilizado para realização da identificação por meio do CANDIFAST (ELITech®) e VITEK® 2 Compact (Biomérieux).

\section{RESULTADOS}

Dentre as amostras analisadas, foram isoladas 22 cepas de leveduras. Utilizando a identificação presuntiva por CHROMagar®, obteve-se dez cepas de C. albicans, que correspondem a 50\%; quatro cepas de C. krusei, com 18\%; duas cepas de C. tropicalis, com 9\%; uma cepa de C. glabrata, com 4,5\%; e quatro cepas de outras espécies de Candida $(18 \%)$.

Ao utilizar o CANDIFAST, 9\% das cepas foram identificadas como C. Iusitaniae, $4,5 \%$ como Saccharomyces sp e $86 \%$ das cepas não foram identificadas.

$\mathrm{Na}$ metodologia automatizada VITEK® 2 Compact, chegou-se aos seguintes resultados: $50 \%$ de $C$. albicans, $9 \%$ de C. tropicalis, $9 \%$ de $C$. parapsilosis, $4,5 \%$ de $C$. glabrata, $4,5 \%$ de $C$. pelliculosa, $4,5 \%$ de $C$. guilliermondii e $18 \%$ de outras leveduras.

Ao analisar o percentual de concordância entre os resultados obtidos nas três metodologias utilizadas, obteve-se o seguinte resultado: 19 cepas tiveram $67 \%$ de concordância e em 3 cepas não houve concordância entre os métodos, conforme Tabela 1. 
Tabela 1 - Identificação das cepas utilizando CHRomagar®, CANDIFAST e VITEK® 2 Compact, com respectivo percentual de concordância

\begin{tabular}{|c|c|c|c|c|}
\hline Amostra & $\begin{array}{l}\text { Identificação por } \\
\text { CHRomagar® }\end{array}$ & $\begin{array}{l}\text { Identificação } \\
\text { por CANDIFAST }\end{array}$ & $\begin{array}{c}\text { Identificação por } \\
\text { VITEK® } 2 \\
\text { Compact }\end{array}$ & $\begin{array}{l}\text { Percentual de } \\
\text { Concordância }\end{array}$ \\
\hline $1 \mathrm{C}$ & C. tropicalis & Não identificado & C. tropicalis & $67 \%$ \\
\hline $2 \mathrm{C}$ & C. albicans & Não identificado & C. albicans & $67 \%$ \\
\hline $2 \mathrm{H}$ & C. albicans & Não identificado & C. albicans & $67 \%$ \\
\hline $3 C$ & C. krusei & Não identificado & Não identificado & $67 \%$ \\
\hline $3 \mathrm{H}$ & C. krusei & $\begin{array}{l}\text { Saccharomyces } \\
s p\end{array}$ & Não identificado & $\mathrm{NHC}$ \\
\hline $4 \mathrm{C}$ & C. krusei & C. Iusitaniae & Não identificado & $\mathrm{NHC}$ \\
\hline $4 \mathrm{H}$ & C. krusei & C. Iusitaniae & Não identificado & $\mathrm{NHC}$ \\
\hline $5 C$ & C. albicans & Não identificado & C. albicans & $67 \%$ \\
\hline $6 C$ & C. tropicalis & Não identificado & C. tropicalis & $67 \%$ \\
\hline $7 \mathrm{C}$ & $\begin{array}{l}\text { outras espécies de } \\
\text { Candida }\end{array}$ & Não identificado & C. parapsilosis & $67 \%$ \\
\hline $8 \mathrm{C}$ & $\begin{array}{l}\text { outras espécies de } \\
\text { Candida }\end{array}$ & Não identificado & C. parapsilosis & $67 \%$ \\
\hline $9 \mathrm{C}$ & C. glabrata & Não identificado & C. glabrata & $67 \%$ \\
\hline $10 \mathrm{C}$ & $\begin{array}{l}\text { outras espécies de } \\
\text { Candida }\end{array}$ & Não identificado & C. pelliculosa & $67 \%$ \\
\hline $11 \mathrm{C}$ & C. albicans & Não identificado & C. albicans & $67 \%$ \\
\hline $12 \mathrm{C}$ & $\begin{array}{l}\text { outras espécies de } \\
\text { Candida }\end{array}$ & Não identificado & C. guilliermondii & $67 \%$ \\
\hline $13 \mathrm{C}$ & C. albicans & Não identificado & C. albicans & $67 \%$ \\
\hline $13 \mathrm{H}$ & C. albicans & Não identificado & C. albicans & $67 \%$ \\
\hline $14 \mathrm{C}$ & C. albicans & Não identificado & C. albicans & $67 \%$ \\
\hline $15 \mathrm{C}$ & C. albicans & Não identificado & C. albicans & $67 \%$ \\
\hline $16 \mathrm{C}$ & C. albicans & Não identificado & C. albicans & $67 \%$ \\
\hline $17 \mathrm{C}$ & C. albicans & Não identificado & C. albicans & $67 \%$ \\
\hline $18 \mathrm{C}$ & C. albicans & Não identificado & C. albicans & $67 \%$ \\
\hline
\end{tabular}

C - Amostra de Cateter Venoso Central

H - Amostra de Hemocultura

NHC - Não houve concordância

Fonte: Autor

Seguindo o protocolo para análise das amostras em Microscopia Eletrônica de Varredura (MEV), constatamos a presença de biofilme em todas as amostras de cateteres.

A Figura 1 mostra a presença de biofilme formado por Candida tropicalis, C. albicans, C. parapsilosis e C. glabrata. 


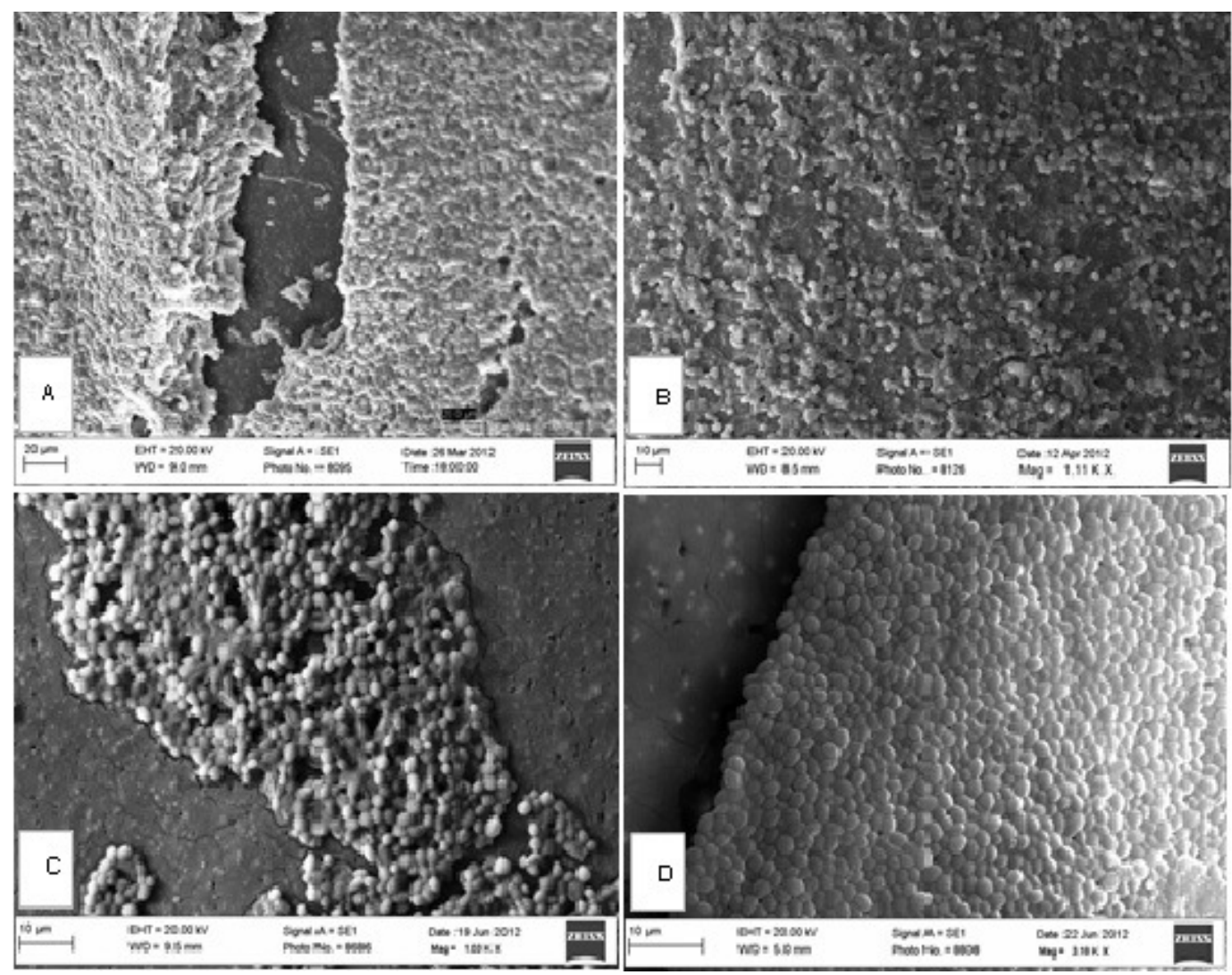

Figura 1 - Visualização de Biofilme: A - Biofilme de $C$. tropicalis em MEV na magnitude de 900X; B - Biofilme de C. albicans em MEV na magnitude de 1000X; C Biofilme de $C$. parapsilosis em MEV na magnitude de 1000X; e D - Biofilme de $C$. glabrata em MEV na magnitude de 3000X.

Fonte: Autor.

Ao analisar os dados fornecidos pelo laboratório particular de microbiologia que cedeu as amostras, foi possível observar que o percentual de pesquisa de ponta de cateter positiva para leveduras (7\%), é menor que as positivas para bacterias e que os micro-organismos mais prevalentes foram: em 1ำ lugar, o Staphylococcus epidermidis, com 16\%; em 2ํㅡ, as Leveduras, com 7\%; e em 3ํ lugar, a Pseudomonas aeruginosa, com 6\%, conforme demonstrado na Figura 2. 


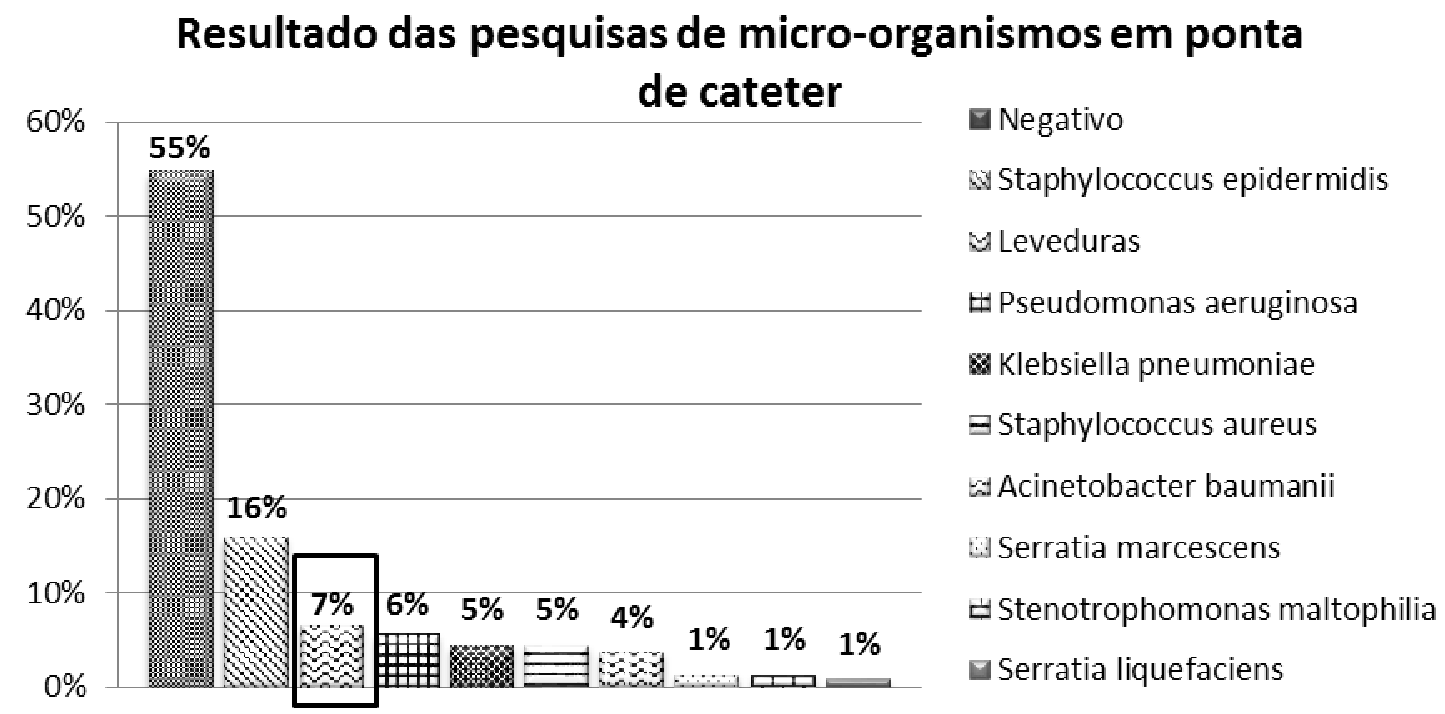

Figura 2 - Avaliação da porcentagem de amostras positivas e negativas obtidas de cateteres de paciente hospitalizados.

Fonte: Autor.

$\mathrm{Na}$ Figura 3 é possível visualizar o resultado de pesquisa de micro-organismos em amostras de cateter e hemocultura do mesmo paciente, sendo que os micro-organismos mais prevalentes foram: Staphylococcus epidermidis com 10\%, Acinetobacter baumanii (8\%), Staphylococcus aureus (8\%), Leveduras (5\%) e Klebsiella pneumoniae (5\%).

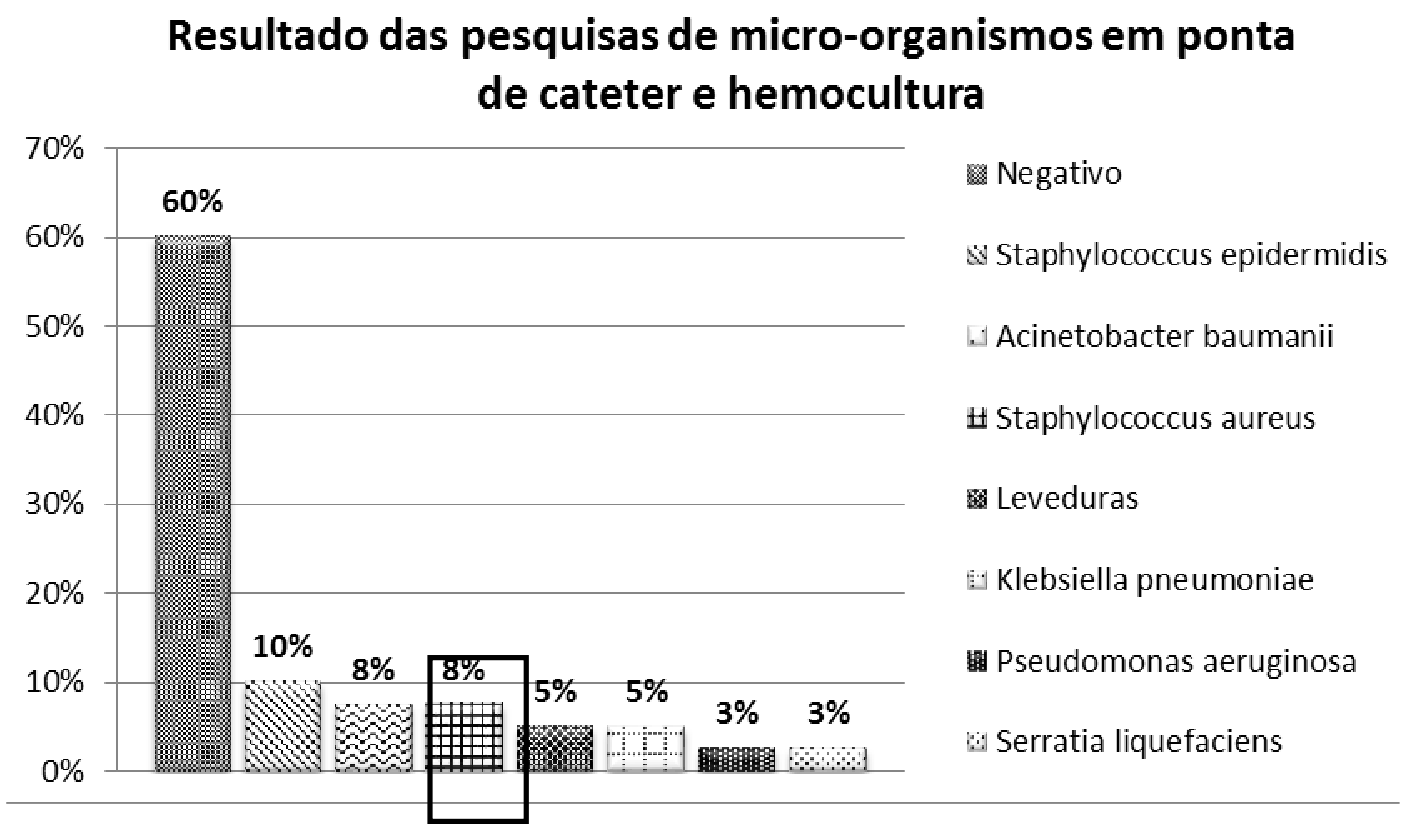

Figura 3 - Avaliação da porcentagem de amostras positivas e negativas obtidas de cateteres e hemoculturas de paciente hospitalizados. Fonte: Autor. 


\section{DISCUSSÃO}

Durante a execução da metodologia proposta por este trabalho, foi possível verificar que a prevalência de $C$. albicans (50\%) em ponta de cateter e hemocultura foi superior em comparação com o número de espécies não-albicans (32\%). Estudo semelhante obteve um resultado concordante, pois, das 23 amostras de leveduras utilizadas (sendo 13 isoladas de cateter venoso central retiradas de pacientes internados na unidade intensiva de tratamento e 10 isoladas das mãos de profissionais que atuam na UTI), a de maior prevalência foi a $C$. albicans, seguida de C. tropicalis e C. parapsilosis (TAMURA et al., 2007).

No que se refere à prevalência de microrganismo, tanto em CVC quanto CVC juntamente com hemocultura, as leveduras aparecem em segundo lugar na colonização de cateter e, em terceiro lugar, na infecção sanguínea relacionada ao CVC (MACHADO et al., 2009).

$\mathrm{Na}$ utilização do CANDIFAST para identificação de leveduras, obteve-se um baixo índice de identificação, cerca de $14 \%$, pois, por se tratar de um método colorimétrico, sua leitura é subjetiva e nem sempre as mudanças de coloração são precisas e reprodutíveis, além de o tempo médio de obtenção de resultado ser de 24 a 48 horas (PEREIRA, 2010). Já, ao executar a metodologia automatizada VITEK® 2 Compact, foi possivel identificar $82 \%$ das amostras em um tempo médio de 18 horas, o que demonstra o bom desempenho do método (PÁROLA, 2011; PEREIRA, 2010).

$\mathrm{Na}$ análise das imagens obtidas pela Microscopia Eletrônica de Varredura, pôde-se observar a presença de biofilme em $100 \%$ das amostras, portanto, apesar da tecnobioengenharia existente na fabricação de CVC, eles ainda estão susceptíveis a formação de biofilme, fato de extrema preocupação, pois contribui para o aumento da morbidade de pacientes que carecem utilizar esses materiais (MACHADO et al., 2009; MACHADO, 2010).

Algumas diferenças que podem existir nas amostras de CVC contaminado com biofilme são: a morfologia dos micro-organismos presentes, espessura e quantidade de biofilme e presença de hifas, podendo estar relacionadas com o estado clínico do paciente, doença de base, uso de medicamentos, tempo de permanência do CVC e, até mesmo, o local de inserção do cateter, porém não foi possível realizar essas correlações devido à falta de acesso ao prontuário dos pacientes. Em duas amostras de CVC e hemocultura do mesmo paciente, verificou-se de concordância entre os micro-organismos presentes, comprovando que o sítio de inserção do cateter está diretamente relacionado com a formação de biofilme e contribuem para a manutenção e surgimento do processo infeccioso sistêmico (MACHADO et al., 2009).

O presente estudo não contou com um número substancial de amostras, devido à dificuldade na obtenção de amostras clínicas de cateter venoso central e uma dificuldade ainda maior na obtenção de amostras de CVC e hemocultura do mesmo paciente, pois essa prática, apesar de preconizada, não é usual no cotidiano hospitalar. 


\section{CONCLUSÃO}

Analisando os dados obtidos pôde-se concluir que a presença de biofilme no cateter é comum e pode influenciar no desenvolvimento de uma candidemia em pacientes hospitalizados e que a metodologia de Microscopia Eletrônica de Varredura, utilizada para avaliação da presença do biofilme, mostrou-se eficiente.

As leveduras foram a segunda maior causa de colonização de CVC e a terceira maior causa de infecção sanguínea relacionada ao uso de CVC. Dentre as leveduras identificadas mais frequentemente, estão: C. albicans com cerca de 50\%, C. tropicalis e C. parapsilosis com $9 \%$ cada uma.

No que tange às metodologias empregadas neste trabalho, concluiu-se que o uso da metodologia VITEK® 2 Compact apresentou um desempenho na identificação de leveduras, além de possuir um menor tempo para liberação do resultado e que CANDIFAST não supriu a necessidade de identificação das leveduras presentes nas amostras, demonstrando, assim, que não existe um único método ideal de identificação desses fungos emergentes, envolvidos em candidemias hospitalares.

\section{REFERÊNCIAS}

ABEGG, P. T. G. M.; SILVA, L. L. Controle de infecção hospitalar em unidade de terapia intensiva: estudo retrospectivo. Semina cienc. biol. saúde, Londrina, v. 32, n. 1, p. 47-58, jan.jun. $2011 . \quad$ Disponível em: $<$ http://www.uel.br/revistas/uel/index.php/seminabio/article/view/3907/8810>. Acesso em: out. 2014.

COIMBRA, M. V. S.; COIMBRA FILHO, M. V. S.; LIMA, N. C. Estudo da prevalência e dos índices de resistência microbiana em um hospital público do Rio de Janeiro. Revisa, Valparaiso de Goiás, v. 1, n. 1, p. 58-67, jan./jun. 2012. ISSN: 2179-0981. Disponível em: <http://revistafacesa.senaaires.com.br/index.php/revisa/article/view/13/10>. Acesso em: out. 2014.

CORRÊA, K. L. G. et al. Diferença de tempo de positividade: método útil no diagnóstico de infecção de corrente sanguínea relacionada com cateter? J. bras. patol. med. Lab., Rio de Janeiro, v. 48, n. 3, p. 195-202; Jun. 2012. Disponível em: <http://www.scielo.br/pdf/jbpml/v48n3/a07v48n3.pdf>. Acesso em: out. 2014.

MACHADO, J. C. et al. Biofilms, Infection, and Parenteral Nutrition Therapy. JPEN J. parenter. enteral nutr., Baltimore, v. 33, n. 4, July/ August, 2009. Disponível em: <http://pen.sagepub.com/content/33/4/397.abstract>. Acesso em: out. 2014.

MACHADO, J. C. Nutroterapia Parenteral, crescimento de biofilmes e fatores associados a infecção do cateter venoso central. 2010. Tese (Doutorado em Clínica Médica). Universidade de São Paulo, São Paulo, 2010. Disponível em: 
<http://www.teses.usp.br/teses/disponiveis/17/17138/tde-20102010-141725/pt-br.php>.

Acesso em: out. 2014.

MIMICA, L. M. J. et al. Diagnóstico de infecção por Candida: avaliação de testes de identificação e caracterização do perfil de susceptibilidade. J. bras. patol. med. lab., Rio de Janeiro, $\quad$ v. $45 ; \quad$ n. 1 ; p. 17-23, 2009. Disponível em: <http://www.scielo.br/pdf/ibpml/v45n1/05.pdf>. Acesso em: out. 2014.

PÁROLA, A. G. Estudo Epidemiológico de Candidíase Invasiva na Unidade de Cuidados Intensivos do Hospital Egas Moniz-Centro Hospitalar Lisboa Ocidental. 2011. Dissertação (Mestrado em Microbiologia Clínica), Faculdade de Medicina de Lisboa, Lisboa, 2011. Disponível em: <http://repositorio.ul.pt/handle/10451/4188>. Acesso em: out. 2014.

PEREIRA, A. P. V. Identificação Molecular de Candidoses invasivas no Centro Hospitalar Cova da Beira, E.P.E. 2010. Dissertação (Mestrado em Ciências Biomédicas). Instituto de Higiene e Medicina Tropical, Universidade Nova de Lisboa, Lisboa. 2010. Disponível em: <http://run.unl.pt/bitstream/10362/5355/1/Tese Ana final.pdf> Acesso em: ago. 2014.

ROSS, C. et al. Análise microbiológica de pontas de cateteres venosos centrais provenientes de pacientes internados no Hospital Universitário da Universidade Estadual de Londrina. Semina cienc. biol. saude, Londrina, v. 27, n. 2, p. 117-123, jul./dez. 2006. Disponível em: <http://www.uel.br/revistas/uel/index.php/seminabio/article/view/3506/2843>. Acesso em: jul. 2014.

SREY, S.; JAHID, I. K.; HA, S. Biofilm formation in food industries: A food safety concern. Food Control, Vurrey, v. 31, n. 2, p. 572-585, June 2013. Disponível em: <http://www.sciencedirect.com/science/article/pii/S0956713512006536>. Acesso em: abr. 2015.

STORTI, A. et al. Biofilme detectado em ponta de cateter venoso central por cultura usando método quantitativo. Rev. bras. anal. clin., v. 39, n. 3, p. 183-187, 2007. Disponível em: <http://www.sbac.org.br/pt/pdfs/rbac/rbac 39 03/rbac 393 06.pdf $>$. Acesso em: jul. 2011.

TAMURA, N. K. et al. Fatores de virulência de Candida spp isoladas de cateteres venosos e mãos de servidores hospitalares. Rev. Soc. Bras. Med. Trop., Brasilia, v. 40, n. 1, p. 91-93, jan./fev. 2007. Disponível em: <http://www.scielo.br/pdf/rsbmt/v40n1/a21v40n1.pdf >. Acesso em: set. 2011.

TAN, S. Y. et al. Emerging frontiers in detection and control of bacterial biofilms. Curr. opin. biotechnol., London, v. 26, p.1-6, 2014. Disponível em: <www.sciencedirect.com>. Acesso em: abr. 2015.

XAVIER, J. B. et al. Monitorização e modelação da estrutura de biofilmes. Bol. Biotecnol., v. 76, p. 2-13, 2003. Disponível em: <http://www.itqb.unl.pt:1111/ jixavier/pucrio/1 introducao/material/jxavier biofilmes.pdf>. Acesso em: dez. 2013. 